T E [ I I I I I i e f

The goal of the Federal Motor Carrier Safety Administration (FMCSA) is to reduce the number and severity of large truck-involved crashes through more commercial motor vehicle and operator inspections and compliance reviews, stronger enforcement measures against violators, expedited completion of rulemaking proceedings, scientifically sound research, and effective commercial driver's license testing, recordkeeping, and sanctions. The Office of Research and Technology manages research and technology development and deployment programs for the FMCSA.

There are eight major research and technology focus areas: crash causation and risk factors; regulatory evaluation and reform; compliance and enforcement; HAZMAT safety and cargo tank integrity; driver training and performance management; driver alertness and fatigue; driver physical qualifications; and car-truck proximity.

Driver physical qualifications concentrates on the research of specific medical conditions in relation to commercial motor vehicle driving safety, with emphasis on medical standards guidelines.

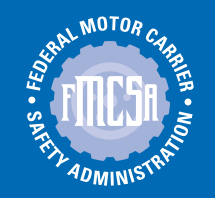

Office of Research and Technology 400 Seventh Street, SW MC-RT; Room 3107 Washington, DC 20590

\title{
Design, Development, and Evaluation of Truck and Bus Driver Wellness Programs
}

\section{Introduction}

In May 1997, the Federal Motor Carrier Safety Administration (FMCSA), formerly the Federal Highway Administration's Office of Motor Carriers, began a research project to design, develop, and evaluate a model truck and bus driver wellness program. This wellness program was developed to provide a resource for addressing truck and bus industry challenges in the area of driver safety, performance, job satisfaction, and industry competition. The program is intended to provide strategies to give drivers opportunities for improved health, benefitting the individual, the company, and the industry.

The program had five primary research tasks. Tasks 1 and 2 consisted of a review of literature regarding commercial motor vehicle (CMV) driver health and current wellness programs, and a draft core wellness program for FMCSA. A survey of 448 experienced, mostly long-haul drivers indicated priority health/wellness concerns, such as lack of family time, lack of exercise, weight, fatigue, poor diet, and stress. Researchers also found that literature on driver health is scarce, and most companies do not have wellness programs.

Tasks 3, 4, and 5 involved the development of the core wellness program, the pilot test and evaluation of the program, and the development of a marketing plan. This tech brief summarizes the study final report, which is the product of tasks 3, 4, and 5: Design, Development and Evaluation of Truck and Bus Driver Wellness Programs.

\section{Purpose}

This wellness program, Gettin' in Gear, was developed to help create awareness and interest in health and wellness within the trucking industry by providing basic health and fitness information to CMV drivers.

\section{Methodology}

Researchers recruited CMV drivers and other trucking industry personnel to participate directly in the development of the Gettin' in Gear wellness program. Drivers and personnel working on the program met over a weekend in Des Moines, IA, in September 1998 to share experiences and ideas used in video, audio and written material to be distributed as part of the program. Trucking

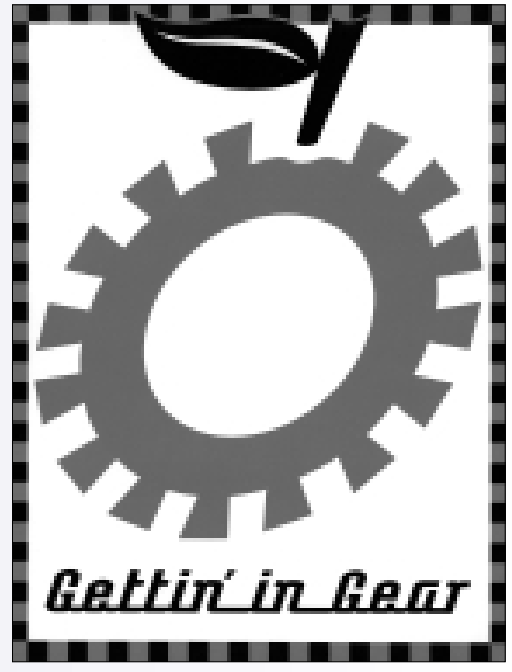

A truck and bus driver wellness program designed by drivers for drivers. 
companies that agreed to participate were provided with recruitment packages to encourage drivers to enroll in the Gettin' in Gear program. Introductory packages, consisting of a brochure, video, audio tape, and notebook were given to each of the 128 participants. The pilot test was scheduled to last 6 months: 1 month to recruit participants, 1 month to introduce the program, and 4 months of driver participation in the program. Health assessments, containing both a written lifestyles questionnaire and a physical risk factor assessment, were completed with each participant. The assessments were given at each pilot trucking company at the same time the introduction to the program was given. The assessment included questions about work environment and health beliefs, blood pressure and heart rate readings, and flexibility, strength, and aerobic fitness tests. All participants had the opportunity to speak with a health professional who explained their results and helped them set personal goals.

Participants in the Gettin' in Gear wellness program received information, both written and audio, mailed directly to their homes for the 4 months of the study. The informative materials were designed to be interactive; for example, each written chapter had worksheets to be completed. The materials addressed the following four topics:

- Refueling - healthy eating habits;

- Relating - value of relationships with family and friends;

- Rejuvenating - health benefits of exercise; and

- Relaxing - managing stress issues.

Each program participant also received a letter from a health professional several times during the 4-month period. Drivers were offered personal coaching by email or toll-free phone number to provide an opportunity for drivers to form a relationship with a health care professional to assist them with lifestyle changes. Some pilot companies provided snacks throughout the study to participants, and all participants were offered a free membership with the Rolling Strong gyms found in several truck stops across the country. One company subsidized YMCA memberships for its participants.

After the 4-month period, all participants were offered follow-up health assessments to collect post-study data on belief, behavior, knowledge, and physical data of participants. Researchers sent letters reminding participants of the follow-up assessment, contacted them by telephone, and worked with pilot company facilitators to schedule drivers.

Follow-up health assessments were performed on 54 of the original 128 drivers. Because of the extremely low follow-up rate, researchers sought to determine whether those who came to the follow-up assessment were the more healthy participants. An analysis of the initial mean health assessment scores of both groups (follow-up and non-follow-up) showed that participants who came back for followup assessments were no healthier than those who did not come back.

\section{Findings}

\section{Health Improvements}

The Gettin' in Gear Program had a positive health impact on the 54 participants measured both initially and at follow-up. This was shown in both lifestyle habits and physical lifestyle data. The most significant improvements were made in the area of exercise and fitness; this is important because this is the area where drivers needed to make the most improvements.

Lifestyle habit data were collected both at the beginning of the study, and at the follow-up health assessment, via questionnaire. Participants recorded their responses to questions in each of the four intervention areas: refueling, relating, rejuvenating, and relaxing. Scores were recorded on a scale of 1 to 5 , with a score of 1 signifying that a driver "almost never" participates in a certain healthy lifestyle activity (e.g., eating vegetables, exercising, or taking time to relax), and a score of 5 meaning that the driver "almost always" does.

The data showed that the participants improved the most in areas where most improvement was needed. Table 1 shows initial and final average questionnaire responses for each of the four categories, along with the difference in scores.

Measurement of physical risk factor data revealed statistically significant improvement in 6 of the 10 areas measured: body mass index (BMI), pulse, diastolic blood pressure, aerobic fitness level, strength fitness level, and flexibility fitness level; the data are shown in Table 2 . The aerobic fitness level of participants was the measure that saw the greatest improvement in the study. The significant improvement in tested fitness level validated a significant improvement in exercise habits.

\section{Driver Acceptance of Program}

In a follow-up assessment, participants were asked questions to help in the evaluation of the wellness program and materials. They rated the overall program a 4.65 on a scale of 1 (low) to 5 (high). Ninety-six percent of participants responded that the program had helped them; drivers commented 
Table 1.

Mean Lifestyle Habit Responses by Category

\begin{tabular}{|l|c|c|c|c|}
\hline Category & Initial Mean & Final Mean & Difference & P Value \\
\hline Rejuvenating & 2.45 & 3.01 & .56 & .004 \\
\hline Refueling & 2.70 & 2.99 & .29 & .03 \\
\hline Relaxing & 3.63 & 3.79 & .16 & .14 \\
\hline Relating & 4.13 & 4.10 & .03 & NS \\
\hline
\end{tabular}

Table 2.

Physical Data ( $\mathrm{N}=54$ )

\begin{tabular}{|l|c|c|c|}
\hline Physical Risk Factor Parameter & Initial Mean & Final Mean & P Value \\
\hline Total Cholesterol (mg\%) & 217 & 218 & NS \\
\hline HDL Percent of Total (\%) & 22 & 21 & NS \\
\hline Glucose (mg\%) & 104 & 104 & NS \\
\hline B.M.I. & 31.7 & 28.6 & .23 \\
\hline Pulse (beats/min) & 73 & 70 & .16 \\
\hline Systolic Blood Pressure (mgHg) & 152 & 148 & NS \\
\hline Diastolic Blood Pressure (mgHg) & 82 & 80 & .18 \\
\hline Aerobic Fitness Score (1) & 2.0 & 3.8 & .00 \\
\hline Strength Fitness Score (2) & 2.1 & 2.7 & .04 \\
\hline Flexibility Fitness Score (3) & 2.2 & 2.5 & .13 \\
\hline
\end{tabular}

* NOTE: 1 (1=Poor, 6=Excellent) 2 (1=Poor, 4=Excellent)

3 (1=Poor, 4=Excellent)

that they are more conscious about eating well, began exercising more often, and have more energy.

Specifically, drivers liked the health assessments and found that having their personal health information was valuable. The notebook and written materials were rated high, but some drivers did not use them. Some drivers enjoyed using the written material and worksheets, others thought it was too timeconsuming. The audio tapes were rated equally as high as the notebook and it seemed that more drivers used the tapes than the notebooks. Drivers did not often use the fitness club memberships and tended to do more exercising on their own. All of the participating drivers responded that they would recommend the program to fellow drivers.

\section{Health Assessment Procedure}

Under ideal conditions, researchers recommend that the health assessment be conducted by a licensed trained health professional. But if the assistance of a health care professional cannot be obtained, the assessment can be modified to be conducted by a layman. Most of the blood work (cholesterol and glucose measures) will still need to be done by a doctor or through a clinic, but the strength, fitness, and flexibility portions of this program can be handled by a trained fleet manager or safety director.

To a layman conducting a health assessment, the elements of coaching and goal setting may present the greatest challenges to implementing a wellness program without professional assistance. The study final report recommends procedures to follow when the health assessment is being conducted by a layman.

\section{Marketing Plans}

There are two primary target audiences to reach with the Gettin' in Gear program: the company decisionmaker and the individual company employee or driver. The decisionmaker is the individual who decides whether to offer a wellness program to employees. The participant is the driver or company employee who recognizes the connection between health habits and safety on the road. 


\section{Researcher}

This study was performed by Sue Roberts Health Concepts, Des Moines, lowa; and Private Fleet Management Institute, National Private Truck Council, Alexandria, Virginia.

\section{Distribution}

This Tech Brief is being distributed according to a standard distribution. Direct distribution is being made to the Service Centers and Divisions.

\section{Avallability}

The study final report will be available from the National

Technical Information Service, Telephone: (703) 605-6000

\section{Key Words}

bus/truck drivers, fitness, nutrition, exercise, health/wellness program, bus/truck drivers training.

\section{Notice}

This Tech Brief is disseminated under the sponsorship of the Department of Transportation in the interest of information exchange. The Tech Brief provides a synopsis of the study's final publication. The Tech Brief does not establish policies or regulations, nor does it imply USDOT endorsement of the conclusions or recommendations. The U.S. Government assumes no liability for its contents or their use.

\section{Web Site}

All FMCSA Tech and Analysis Briefs may be accessed at: http://www.fmcsa.dot.gov.

\section{Technical Writer}

Hallie Magyar, Avalon Integrated Services.

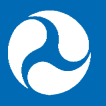

U.S. Department of Transportation Federal Motor Carrier Safety Administration

June 2000

Publication No. FMCSA-MCRT-00-011
There are several recommended marketing strategies for the Gettin' in Gear program. One is a large group marketing presentation to present the results of the pilot study to decisionmakers at various meetings across the U.S. The presentations will improve decisionmaker awareness of the importance of health to their bottom line, present data from the pilot study showing health improvements made with the program, and inform decisionmakers how they might use the Gettin' in Gear program with their employees.

Another marketing strategy is a "train the trainer" presentation, the objective of which is to convince decisionmakers to implement the Gettin' in Gear program in their workplaces and to provide them with resources needed to implement the program.

Project researchers also recommend that a promotional campaign be conducted to make information available to the transportation industry about the Gettin' in Gear program. Suggestions include developing an announcement and press kit folder to be sent to companies within the industry and the placement of articles and print ads in industry publications to announce the Gettin' in Gear program and discuss driver wellness. 